\title{
Maritime hominin dispersals in the Pleistocene: advancing the debate
}

\author{
Thomas P. Leppard ${ }^{1, *} \&$ Curtis Runnels $^{2}$
}

\section{Introduction: oceans as inhibitors or enablers of dispersal?}

To what extent is there spatial and temporal patterning in the spread of our genus around the planet, and what environmental and behavioural factors specify this patterning? The prevailing model of Pleistocene dispersals of Homo holds that this process was essentially terrestrial, with oceans and seas inhibiting and directing the movement of hominins out of Africa (e.g. Mellars 2006; Dennell \& Petraglia 2012; Gamble 2013), although some scholars propose short-range maritime hops at both the Strait of Gibraltar and Bab-elMandeb (Lambeck et al. 2011; Rolland 2013). The relatively recent discovery of stone tools with apparently Lower and Middle Palaeolithic characteristics on islands in the eastern Mediterranean and in Island Southeast Asia (ISEA) has, however, been used by some scholars to challenge this terrestrial model.

The most extensive-if still contentious-data come from Flores in the Lesser Sundas, where sites in the So'a Basin provide the earliest dates for hominin presence on the island. The chipped stone assemblage from Wolo Sege dates to 1.02 Mya (Brumm et al. 2010), while a mandible fragment and isolated teeth from Mata Menge, assigned to $H$. floresiensis on a morphological basis, and found in association with non-hominin taxa as well as chipped stone artefacts, are dated to 0.7 Mya (Brumm et al. 2016; van den Bergh et al. 2016a), much earlier than the controversial (e.g. Henneberg et al. 2014), if now re-dated (Sutikna et al. 2016), fossil evidence provided by specimen LB1. Examples of islands devoid of fossil data, yet with purported pre-Upper Palaeolithic artefacts, include Sulawesi, to the north of the Lesser Sundas across the Flores Sea (van den Bergh et al. 2016b), and a number of Mediterranean islands, most notably the Greek islands of Crete, Gavdos, Naxos and potentially Melos and Kephalonia (Strasser et al. 2010; Carter et al. 2014; Runnels 2014a). The stone tools reported from the Greek islands have Lower and Middle Palaeolithic morpho-typological characteristics, and some have associated radiometric dates that suggest that they are late Middle Pleistocene in age, if not earlier (Strasser et al. 2011; Runnels et al. 2014). These islands have probably remained insular throughout glacially driven Quaternary sea-level oscillations (van der Geer et al. 2014; Sakellariou \& Galanidou 2015; but cf. Lykousis 2009), and thus these data have been interpreted as indicative of a hitherto unexpected capacity among archaic hominins for intentional maritime dispersal as early as the mid-Lower Palaeolithic (Simmons 2012, 2014; Runnels 2014a).

1 McDonald Institute for Archaeological Research, University of Cambridge, Downing Street, Cambridge CB2 3ER, $U K$

2 Department of Archaeology, Boston University, 675 Commonwealth Avenue, Boston, MA 02215, USA

* Author for correspondence (Email: tpl26@cam.ac.uk) 
If this revisionist maritime model is supported by future research, it could radically destabilise our current understanding of the structure of hominin dispersals. Other scholars, however, have hesitated to accept either the Palaeolithic credentials of the lithic artefacts, or the likelihood of intentional maritime dispersal potentially implied by them (e.g. Broodbank 2013: 82-108, 2014). We ourselves have disagreed substantively on this issue; yet despite one of us (CR) being a major proponent of the revisionist maritime model (e.g. Runnels 2014a \& b; Runnels et al. 2014), and the other (TPL) a serial critic of it (e.g. Leppard 2014, 2015a \& b), we find that we are nevertheless in full agreement on two major issues connected with the debate. First, this topic is of profound importance for the archaeology of hominin dispersal, with broader implications for cognitive evolution in Homo. If we have fundamentally misunderstood environmental constraints on, and the spatial structure of, hominin dispersal, then serious aspersions would be cast both on models of tempo and gradient of the evolution of behavioural plasticity, and on our ability to recognise the presence versus absence of Palaeolithic occupation (or necessitate providing a revised account of why many islands do seem to lack such occupation). Second, as a function of this recognition, we agree that the utmost clarity —of expression, of definition of the problem at hand and of articulation of question-led research, the absence of which can only further cloud already murky waters - needs to be brought to a well-defined body of data. This is the goal of our present contribution: to frame how we perceive the problem in terms that are as precise as possible; and, based on this, to outline how we may better bring theory, method and data to bear on this issue so that we might move towards understanding whether archaeologists have accurately grasped — or not—-the broad outline of how, and in what terms, hominins spread around the planet.

\section{Clarifying the debate}

We suggest that a number of trends can be identified that have prevented this debate from moving forward, not least different terminologies being employed for different ends (e.g. the nuanced but significant distinction between Broodbank (2014: 269) and Runnels (2014b: 274) regarding definitions of voyaging and seafaring). We do not dwell here on the spectrum of ecodynamic and behavioural processes implied by the commonly used term 'colonisation', which has a wide range of possible definitions, mostly referring to permanent, year-round settlement, and which is most appropriate for the activities of modern humans in the Holocene (see Cherry 1981; Dawson 2014: 42-68). For human dispersals in the Pleistocene, very different terms from colonisation may be apt, and it is sufficient to note that detailed specificity regarding the type and degree of activity under discussion can only improve clarity, especially when underdetermined phraseologies have very different meanings for scholars working at opposite ends of the Pleistocene (and into the Holocene). We also note that the tacit reliance on varying standards of evidence when evaluating claims for early island occupation-as well as differences between implicitly deductive and inductive approaches to the material—has also clouded the picture; do we require deeply stratified sites with suites of absolute dates, or are morpho-typologically Palaeolithic surface assemblages adequate? We disagree on the answer (and explore the issue in greater detail below); but we agree completely that it is necessary to be explicit about which 
position is being endorsed and the degree of scepticism with which the dataset is being approached.

A more substantial obstacle to progress in this discussion is the potential to conflate three interrelated but discrete research problems. The first problem involves the possibility of maritime dispersals by archaic species of Homo, particularly $H$. erectus sensu lato and heidelbergensis (as well as neanderthalensis and anatomical moderns from around 300-200 kya) during the Lower and Middle Palaeolithic (Bednarik 2003; Dennell et al. 2014). The second problem relates to the extent and form of seagoing and colonising behaviour among behavioural moderns practising hunting-gathering-fishing following their arrival in ISEA and the circum-Mediterranean, and yet prior to the advent of agropastoral lifestyles (Broodbank 2006; Phoca-Cosmetatou \& Rabett 2014). A third and final problem involves patterning in Early-Mid Holocene seagoing and colonising behaviour by behavioural Moderns practising various forms of agropastoralism (Cherry 1981, 1990; Broodbank 2006). We argue that the explicit recognition of these research problems is essential if we are to escape conflation of these individual issues and the terms in which they are defined. The substantial behavioural, cognitive and social differences between, for example, Lower and Upper Palaeolithic contexts suggests that apparent patterning might derive from very different structuring factors. Despite accumulating evidence for sporadic activity, the general reluctance on the part of behavioural moderns in the aftermath of the Last Glacial Maximum (LGM) to exploit island environments is potentially a function of the general unattractiveness of islands to hunter-gatherer-fisher populations, perhaps relating to the intrinsic trophic limitations of comparatively small habitat fragments (Brose et al. 2004). That is, we might understand this apparent lack of interest in small islands to be a function of insular energetic limitations relating to viable range and group size, rather than an outcome of strictly biogeographic barriers to dispersal; terminal Upper Palaeolithic communities were, after all, demonstrably capable of reaching Mediterranean islands (Broodbank 2006). By contrast, the absence of, for example, Australopith populations from the insular Mediterranean (or, indeed, from anywhere outside sub-Saharan Africa) is more readily comprehensible as an outcome of biogeographic and behavioural constraints.

In short, the evidence for seagoing and island colonisation by behavioural moderns during the initial Holocene is probably irrelevant in the context of understanding potential trans-maritime dispersal in species separated by evolutionary time and genetic distance, just as research on possible Neanderthal island exploitation in the Ionian Sea is unlikely to be useful in considering why Early Neolithic farmers were reluctant to settle the Balearics permanently. These problems differ in their assumptions about which hominin species were involved, the cognitive architecture and social organisation of these species, palaeoenvironmental conditions and palaeogeographic reconstructions. New data or models pertaining to one problem do not necessarily pertain to another. It is this first issue-the possibility of deliberate maritime dispersal as a hominin behaviour with a deep antiquity - that poses the greatest challenge to the received Palaeolithic consensus; the ability of behavioural moderns to traverse substantial water gaps, and their general, surprising recalcitrance in doing so prior to the Neolithic, is a topic for another venue.

(C) Antiquity Publications Ltd, 2017 


\section{Advancing the debate}

Having clarified what it is we wish to know more about, how might we move the discussion forward? We identify intrinsic limitations in the data, and highlight possible pathways towards mitigating the effects of these limitations. In so doing, we tentatively sketch an agenda for more rigorously evaluating claims for maritime hominin dispersal in the Pleistocene.

\section{Intrinsic limitations in the data: the Robinson Crusoe problem}

From the perspective of research design and data recovery, developing answers to the question of Early and Middle Pleistocene sea-crossing dispersals is impeded by a methodological issue: the 'Robinson Crusoe' problem. Small-scale or short-term hominin activity on islands - 'Robinson Crusoe events'-during the Palaeolithic will be inconspicuous archaeologically because of stochastic effects having a bearing on the taphonomy and recovery of small datasets. Other factors being equal, the greater the temporal and spatial extent (and material complexity) of a behavioural phenomenon, the greater should be its archaeological visibility; the frequency of Robinson Crusoe events (isolated crossings, whether intentional or passive (Dennell et al. 2014), followed by extinction or even potentially departure) is, then, likely to be inverse to their archaeological visibility (Leppard 2015a). While current research designs - specifically traditional site excavations and diachronic regional pedestrian surveys_are effective in identifying large-scale and long-term, materially rich behavioural phenomena, they are less suited to identifying small-scale and/or short-term maritime dispersal and island occupation events. As there is reason to suppose (in terms of probable behavioural and organisational scenarios) that any potential maritime dispersal during the Pleistocene would closely resemble a Robinson Crusoe event, it is probable that the suggestive yet patchy evidence that we currently possess represents the richest dataset possible. An immediate practical lesson is that waiting for a deluge of high-quality, overlapping, insular Pleistocene data is unlikely to prove a fruitful avenue of research; we must necessarily deal with the data that we have, rather than indefinitely postpone their evaluation.

The problem of sparse yet potentially very significant data relating to hominin dispersal across or into less biogeographically optimal zones is, of course, not restricted to island environments. Recent claims have been made-to provide two examples-for pre-LGM high- (as opposed to mid-) latitude presence of moderns during early-middle Marine Isotope Stage 3 (Pitulko et al. 2016), and for precociously early extra-African chipped stone industries and associated types of behaviour (Malassé et al. 2016). The implications for models of cognitive, technological and social change in Homo are extensive; yet how are we to evaluate claims that rest on small evidential foundations? One conceptual solution involves dealing explicitly with long-term trajectories of success or failure. Bar-Yosef (in press) emphasises that we are methodologically ill-equipped both to identify comparatively rapid settlement failure, and to distinguish the successful, long-term establishment of settlement from repeated short-term failures. This is because sporadic recovery and capricious taphonomic process may conspire to give periods of established, long-term settlement the appearance, archaeologically, of repeated cycles of colonisation and failure. Successful establishment of Homo in an environment that we might consider comparatively challenging in terms of the complexity of behaviour and degree of encephalisation of the 
species in question is probably likely to have greater palaeoanthropological significance overall than unsuccessful establishment deriving from environmental demands (broadly conceived) exceeding the degree of adaptive plasticity in the respective species.

This distinction can be illuminated by the temporally punctuated Flores data. Is the separation of bodies of both fossil and artefact evidence by substantial temporal lacunae (Brumm et al. 2010; Gómez-Robles 2016; Sutikna et al. 2016) indicative of repeated colonisation followed by localised extinction, or of long-term and successful settlement that is archaeologically inconspicuous because of the small numbers involved and the vagaries of observation in a heterogeneous sampling universe? The answer is not clear (although, in the Flores instance, the probable time required for a taxon to undergo island dwarfing as part of an allopatric speciation process may suggest the latter (e.g. Bromham \& Cardillo 2007)), but Bar-Yosefs point has implications for how we conceptualise potential pre-Holocene maritime dispersal events. The ecodynamic intersection between insular environments and an archaic hominin modus vivendi may mean that any maritime dispersal event resulted in unsuccessful settlement in the long term, rather than resulting in a continued presence (the usual connotation of the term colonisation) that we are failing to identify archaeologically.

Recognising that inherently patchy data may derive from-and more importantly further clarify - the type of post-dispersal establishment processes with which we are dealing (i.e. long-term success versus reiterated failure) does little to resolve the question of the nature of initial dispersal. Useful models do, however, exist that may serve to develop our understanding of how, if at all, archaic hominins traversed water gaps.

\section{Modes of dispersal and structural homologies on the Eurasian fringe}

Future research must be contextualised within the wider debate in Pleistocene archaeology and palaeoanthropology. We note, in particular, the development within the scholarship on ISEA archaeology of more nuanced models of dispersal. Dennell et al. (2014) have explored the possibility that the presence of a species of hominin on a given landmass-they focus on Wallacea, but the concept can be generalised-may not necessarily be indicative of choices reflecting strategic dispersal goals. Turning to the literature on modes of dispersal in non-human taxa (e.g. de Quieroz 2014), one of us (Leppard 2015a) has speculated whether passive, rather than active or strategic, dispersal events could account in principle for dispersal of archaic hominins across water gaps. Recognising that non-human taxa cross biogeographic barriers in a probabilistic fashion, we can ask whether this mode of dispersal has any explanatory power in accounting for hominin dispersal; if it has this potential, how should we balance invoking passive versus active/strategic dispersal in accounting for purported maritime crossings?

Thinking along these eco-geographical lines, it is worth highlighting conceivably relevant contextual similarities between the Mediterranean and ISEA. Despite evident environmental variability, there are structural homologies: both contexts are mid- to low-latitude, comparatively shallow seas situated—mostly—on continental shelves. Glacial-insterstadial oscillations have therefore affected their palaeogeography substantially; in both instances, cyclically exposing and inundating large swathes of potentially productive habitats. Both ISEA and the Mediterranean comprise groups of large and ecologically robust islands that (C) Antiquity Publications Ltd, 2017 
have remained insular throughout these eustatic oscillations, islands that are nonetheless proximate to the Eurasian mainland and its evidence for the long-term persistence of archaic hominin metapopulations (Broadfield et al. 2001; Carbonell et al. 2008). These conditions facilitated maritime dispersal in other large-bodied mammals, and may have encouraged the intentional short-distance dispersal of Neanderthals in the Mediterranean (Broodbank 2006, 2014), as well as passive dispersal of $H$. erectus sensu lato in ISEA and potentially the Mediterranean (Dennell et al. 2014; Leppard 2014). The lack of evidence for archaic hominins from, for example, Madagascar or the North Atlantic volcanic islands-structurally unsuitable contexts for successful passive dispersal-further hints at the applicability of biogeography and dispersal studies of non-human taxa for interpreting this patterning.

Finally, in terms of developing robust bodies of theory for interrogating suggestive data, we highlight the interest amongst scholars who deal with maritime dispersal in moderns in using palaeoenvironmental data to refine models of colonisation (Burney 1997; Rick et al. 2013). The essential working assumption is that human colonisation should be accompanied by various types of environmental reorganisation (both direct, such as firesetting and exploitation of endemic biota; and indirect, such as disruptions in nutrientcycling deriving from trophic reorganisation in disturbed ecologies), which should be visible in the palaeoenvironmental record. There are reasons to suppose that the ecological impacts of agropastoral modern humans may be substantially greater than, or differ from, parallel types of impact in more archaic species. Even so, a productive avenue into assessing the probable nature and scale of any pre-modern maritime dispersal events may involve modelling probable types of hominin palaeoenvironmental impact (Phoca-Cosmetatou \& Rabett 2014), particularly in terms of predation pressure affecting relative frequencies of taxa and subsequent assessment of the degree of correlation between the model and relevant datasets. In essence, the arrival of hominins in a previously insulated ecosystem should be visible as a series of processes in proxy records other than the archaeological.

\section{Investigation and demonstration of maritime hominin dispersals in the Pleistocene}

While we continue to disagree about the degree and type of evidence required to demonstrate maritime dispersals during the Pleistocene, we agree completely on probable pathways of productive investigation. Our goal is not to prescribe best practice, but to highlight strategies that are likely to generate data that help to clarify rather than obfuscate potential conclusions.

We suggested above that modes of fieldwork that are common in the Mediterranean (less so in ISEA) will be intrinsically inefficient in identifying the type of phenomenon in which we are interested. Accordingly, it is hard to be sure whether the continued absence of evidence that might be interpreted as Lower-Middle Palaeolithic on some Mediterranean islands reflects Pleistocene behaviour or is an artefact of research. This is exacerbated by the lack of detailed palaeoenvironmental and palaeogeographical data for many areas, inhibiting the construction of robust chronostratigraphies. Testing hypotheses about archaic hominin maritime dispersals via archaeological data necessitates research designs involving 'targeted' pedestrian surveys, such as those used successfully in Greece (Runnels et al. 2005; Strasser et al. 2010), and the investigation of niches likely to have been a focus of any hominin 
activity. Targeted surveys focus attention on geological and pedological contexts (identified after suitable palaeoenvironmental and palaeogeographic reconstructions) that have a high probability of preserving remains of the cultural phase of interest. Such surveys are indispensable — a point not always recognised — for identifying Palaeolithic remains that are not 'sites' in the usual sense (i.e. not deeply stratified), but more often clusters of stone tools, forming surface signatures on geologic outcrops or in lag deposits on palaeosurfaces, which represent brief bursts of activity amongst non-sedentary populations (Runnels 2014a).

Clearly, the more direct archaeological evidence we have, and the better-dated this evidence, the more convincing will be associated claims for Pleistocene maritime dispersal. Accepting, however, that artefact clusters on lag deposits are, in many cases, likely to represent best-case scenarios in terms of strictly archaeological data, palaeoenvironmental records (i.e. fossil, sub-fossil, palynological) offer useful means of assessing ecosystem disturbance likely to accompany the arrival of Homo in a previously insulated context. We stress that a series of behaviourally plastic invasive species in the higher echelons of trophic systems colonising habitats hitherto free of such species should drive direct but also indirect ecosystemic change, and that this should be visible to a degree in environmental proxies. Not only more obvious examples of such proxies (such as direct evidence for predation or scavenging as evidenced by butchery marks or peri-mortem trauma), but also less obvious: asymmetric disturbance in herbivorous taxa driving dynamism in pollen deposition, for example, or behavioural adaptations in prey species reflected in stable isotope records.

Imaginative modelling of hominin environmental impacts will provide additional means, beyond contentious archaeological data, to evaluate claims for Pleistocene dispersal and colonisation. In general, maximising the qualitative and quantitative richness of data, driven by question-led fieldwork and complementary palaeoenvironmental studies (alongside the appropriate use of analogical argumentation, e.g. Cherry \& Leppard 2015; HowittMarshall \& Runnels 2016), represents the best chance for advancing our understanding of hominin dispersal across biogeographic barriers.

\section{Discussion}

Did seas and oceans inhibit the spread of our genus around the planet, as has generally been assumed? Or did they instead enable the dispersal of hominins during the Early and Middle Pleistocene? There is much at stake here. The answer will have major implications for our understanding of the spatial and temporal structure of early human dispersal. If large expanses of open water inhibited archaic hominin movement, we can continue to rely upon the still dominant terrestrial model in understanding the peopling of Eurasia, and rule out contact of archaic hominins with insular Quaternary landmasses such as Australia/Sahul, Oceania and beyond to the Americas (recognising that, Pitulko et al. (2016) notwithstanding, Beringia remained too far north to constitute an effective land bridge until late in the Pleistocene). Conversely, if it is demonstrated that open seacrossings enabled archaic hominin dispersals between landmasses, this would revolutionise our understanding of the human diaspora across the globe.

The implications are not limited to dispersal. Intrinsic to our current understanding of the structure of the spread of our genus in spatial and temporal terms is an assumption that (C) Antiquity Publications Ltd, 2017 
this structure in part derives from the ability, incrementally increasing through evolutionary time, of Homo to overcome certain types of environmental restriction: that is, of more complex neurocognitive architecture allowing increasingly flexible behavioural responses to otherwise hostile environments (e.g. Davidson \& Noble 1992; Davidson 2010, 2013; Leppard 2015b; Howitt-Marshall \& Runnels 2016). If, in fact, there is no reason to suppose that the capacity to access and exploit challenging niches is related to cognitive evolution, and archaic Homo was undertaking long-distance dispersal in the Early and Middle Pleistocene, then discussions of 'behavioural modernity' will require substantial revision. In this sense, many archaeologists-working in diverse research contexts-are stakeholders in this debate. All the more reason for urging caution, clarity of expression and intellectual openness as we pursue the research agenda sketched here.

\section{Acknowledgements}

We are extremely grateful to the two reviewers for their considered and illuminating comments on an earlier draft of this paper. We are particularly thankful to Robin Dennell for his detailed and insightful reaction to that draft, and we acknowledge his assistance in clarifying and framing the second half of the manuscript.

\section{References}

BAR-Yosef, Y. In press. Facing climatic hazards: Paleolithic foragers and Neolithic farmers. Quaternary International. https://doi.org/10.1016/j.quaint.2015.11.037

BEDNARIK, R.G. 2003. Seafaring in the Pleistocene. Cambridge Archaeological Journal 13: 41-66. https://doi.org/10.1017/S0959774303000039

Broadfield, D.C., R.L. Holloway, K. Mowbray, A. Silvers, M.S. Yuan \& S. Márquez. 2001. Endocast of Sambungmacan 3 (Sm 3): a new Homo erectus from Indonesia. The Anatomical Record 262: 369-79. https://doi.org/10.1002/ar.1047

Bromham, L. \& M. Cardillo. 2007. Primates follow the 'island rule': implications for interpreting Homo floresiensis. Biology Letters 3: 398-400. https://doi.org/10.1098/rsbl.2007.0113

Broodbank, C. 2006. The origins and early development of Mediterranean maritime activity. Journal of Mediterranean Archaeology 19: 199-230. https://doi.org/10.1558//jmea.2006.v19i2.199

- 2013. The making of the Middle Sea: a history of the Mediterranean from the beginning to the emergence of the Classical world. London: Thames \& Hudson.

- 2014. So ... what? Does the paradigm currently want to budge so much? Journal of Mediterranean Archaeology 27: 267-72. https://doi.org/10.1558/jmea.v27i2.267

Brose, U., A. Ostling, K. Harrison \& N.D. Martinez. 2004. Unified spatial scaling of species and their trophic interactions. Nature 428: 167-71. https://doi.org/10.1038/nature02297
Brumm, A., G.M. Jensen, G.D. van den Bergh, M.J. Morwood, I. Kurniawan, F. Aziz \& M. Storey. 2010. Hominins on Flores, Indonesia, by one million years ago. Nature 464: 748-52. https://doi.org/10.1038/nature08844

Brumm, A., G.D. van den Bergh, M. Storey, I. Kurniawan, B.V. Alloway, R. Setiwan, E. Setiyabudi, R. Grün, M.W. Moore, D. Yurnaldi, M.R. Puspaningrum, U.P. Wibowo, H. Insani, I. Sutisna, J.A. Westgate, N.J.G. Pearce, M. Duval, H.J.M. Meijer, F. Aziz, T. Sutikna, S. van der Kars, F. Flude \& M.J. Morwood. 2016. Age and context of the oldest known hominin fossils from Flores. Nature 534: 249-53. https://doi.org/10.1038/nature17663

Burney, D.A. 1997. Tropical islands as paleoecological laboratories: gauging the consequences of human arrival. Human Ecology 25: 437-57. https://doi.org/10.1023/A:1021823610090

Carbonell, E., J.M. Bermúdez de Castro, J.M. Parés, A. Pérez-González, G. Cuenca-Bescós, A. Ollé, M. Mosquera, R. Huguet, J. van der Made, A. Rosas, R. Sala, J. Vallverdú, N. García, D.E. Granger, M. Martinón-Torres, X.P. Rodríguez, G.M. Stock, J.M. Vergès, E. Allué, F. Burjachs, I. Cáceres, A. Canals, A. Benito, C. Díez, M. Lozano, A. Mateos, M. Navazo, J. Rodríguez, J. Rosell \& J.L. Arsuaga. 2008. The first hominin of Europe. Nature 452: 465-69. https://doi.org/10.1038/nature06815 
Carter, T., D. Contreras, S. Doyle, D.D. Mihailović, T. Moutsiou \& N. Skarpelis. 2014. The Stélida Naxos Archaeological Project: new data on the Middle Palaeolithic and Mesolithic Cyclades. Antiquity 88(341): Project Gallery. Available at: http://antiquity.ac.uk/projgall/carter341 (accessed 9 January 2017).

Cherry, J.F. 1981. Pattern and process in the earliest colonization of the Mediterranean islands. Proceedings of the Prehistoric Society 47: 41-68. https://doi.org/10.1017/S0079497X00008859

- 1990. The first colonization of the Mediterranean islands: a review of recent research. Journal of Mediterranean Archaeology 3: 145-221.

Cherry, J.F. \& T.P. Leppard. 2015. Experimental archaeology and the earliest seafaring: the limitations of inference. World Archaeology 47: 740-55. https://doi.org/10.1080/00438243.2015.1078739

Davidson, I. 2010. The colonisation of Australia and its adjacent islands and the evolution of modern cognition. Current Anthropology 51 (supplement 1): 177-89. https://doi.org/10.1086/650694

- 2013. Peopling the last new worlds: the first colonisation of Sahul and the Americas. Quaternary International 285: 1-29. https://doi.org/10.1016/j.quaint.2012.09.023

Davidson, I. \& W. Noble. 1992. Why the first colonisation of the Australian region is the earliest evidence of modern human behaviour. Archaeology in Oceania 27: 135-42. https://doi.org/10.1002/ j.1834-4453.1992.tb00297.x

Dawson, H. 2014. Mediterranean voyages: the archaeology of island colonisation and abandonment (Institute of Archaeology Publications 62). Walnut Creek (CA): Left Coast.

Dennell, R. \& M.D. Petraglia. 2012. The dispersal of Homo sapiens across southern Asia: how early, how often, how complex? Quaternary Science Reviews 47: 15-22. https://doi.org/10.1016/j.quascirev.2012.05.002

Dennell, R., J. Louys. H.J. O’Regan \& D.M. Wilkinson. 2014. The origins and persistence of Homo floresiensis on Flores: biogeographical and ecological perspectives. Quaternary Science Reviews 96: 98-107. https://doi.org/10.1016/j.quascirev.2013.06.031

DE Quieroz, A. 2014. The monkey's voyage: how improbable journeys shaped the history of life. New York: Basic.

Gamble, C. 2013. Settling the earth: the archaeology of deep human history. Cambridge: Cambridge University Press. https://doi.org/10.1017/CBO9781139003933
Gómez-Robles, A. 2016. The dawn of Homo floresiensis. Nature 534: 188-89. https://doi.org/10.1038/534188a

Henneberg, M., R.B. Eckhardt, S. Chavanaves \& K.J. Hsü. 2014. Evolved developmental homeostasis disturbed in LB1 from Flores, Indonesia, denotes Down syndrome and not diagnostic traits of the invalid species Homo floresiensis. Proceedings of the National Academy of Sciences of the USA 111: 11967-72. https://doi.org/10.1073/pnas.1407382111

Howitt-Marshall, D. \& C. Runnels. 2016. Middle Pleistocene sea-crossings in the eastern Mediterranean? Journal of Anthropological Archaeology 42: 140-53. https://doi.org/10.1016/j.jaa.2016.04.005

Lambeck, K., A. Purcell, N.C. Flemming, C. Vita-Finzi, A.M. Alsharekh \& G.N. Bailey 2011. Sea level and shoreline reconstructions for the Red Sea: isostatic and tectonic considerations and implications for hominin migration out of Africa. Quaternary Science Reviews 30: 3542-74. https://doi.org/10.1016/j.quascirev.2011.08.008

LEPPARD, T.P. 2014. Modeling the impacts of Mediterranean island colonization by archaic hominins: the likelihood of an insular Lower Palaeolithic. Journal of Mediterranean Archaeology 27: 231-54. https://doi.org/10.1558/jmea.v27i2.231

- 2015a. Passive dispersal versus strategic dispersal in island colonization by hominins. Current Anthropology 56: 590-95. https://doi.org/10.1086/682325

$-2015 \mathrm{~b}$. The evolution of modern behaviour and its implications for maritime dispersal during the Palaeolithic. Cambridge Archaeological Journal 25: 829-46. https://doi.org/10.1017/S0959774315000098

Lyкоusıs, V. 2009. Sea-level changes and shelf break prograding sequences during the last $400 \mathrm{ka}$ in the Aegean margins: subsidence rates and palaeogeographic implications. Continental Shelf Research 29: 2037-44. https://doi.org/10.1016/j.csr.2008.11.005

Malassé, A.D., A.-M. Moigne, M. Singh, T. Calligaro, B. Karir, C. Gaillard, A. Kaur, V. Bhardwaj, S. Pal, S. Abdessadok, C.C. Sao, J. Gargani, A. Tudryn \& M.G. Sanz. 2016. Intentional cut marks on bovid from the Quranwala zone, 2.6 Ma, Siwalik Frontal Range, northwestern India. Comptes Rendus Palevol 15: 317-39. https://doi.org/10.1016/j.crpv.2015.09.019 
Mellars, P. 2006. Why did modern human populations disperse from Africa ca. 60,000 years ago? A new model. Proceedings of the National Academy of Sciences of the USA 103: 9381-86. https://doi.org/10.1073/pnas.0510792103

Phoca-Cosmetatou, N. \& R.J. Rabett. 2014. Pleistocene island occupation in the Mediterranean: insights from a tied-biome approach to glacial refugia, in K. Boyle, R.J. Rabett \& C.O. Hunt (ed.) Living in the landscape: essays in honour of Graeme Barker: 83-108. Cambridge: McDonald Institute for Archaeological Research.

Pitulko, V.V., A.N. Tikhonov, E.Y. Pavlova, P.A. Nikolskiy, K.E. Kuper \& R.N. Polozov. 2016. Early human presence in the Arctic: evidence from 45,000-year-old mammoth remains. Science 351: 260-63. https://doi.org/10.1126/science.aad0554

Rick, T.C., P.V. Kirch, J.M. Erlandson \& S.M. FitzPatrick. 2013. Archeology, deep history, and the human transformation of island ecosystems. Anthropocene 4: 33-45. https://doi.org/10.1016/j.ancene.2013.08.002

Rolland, N. 2013. The early Pleistocene human dispersals in the circum-Mediterranean basin and initial peopling of Europe: single or multiple pathways? Quaternary International 316: 59-72. https://doi.org/10.1016/j.quaint.2013.06.028

Runnels, C. 2014a. Early Palaeolithic on the Greek islands? Journal of Mediterranean Archaeology 27: 211-30. https://doi.org/10.1558/jmea.v27i2.211

- 2014b. Response: where do we stand? Journal of Mediterranean Archaeology 27: 272-74. https://doi.org/10.1558/jmea.v27i2.272

Runnels, C., E. Panagopoulou, P. Murray, G. Tsartsidou, K. Mullen \& E. Tourloukis. 2005. A Mesolithic landscape in Greece: testing a site-location model in the Argolid at Kandia. Journal of Mediterranean Archaeology 18: 259-85. https://doi.org/10.1558/jmea.2005.18.2.259

Runnels, C., C. Digregorio, K.W. Wegmann, S.F. Gallen, E. Panagopoulou \& T.F. Strasser. 2014. Lower Palaeolithic artifacts from Plakias, Crete: implications for hominin dispersals. Eurasian Prehistory 11(1-2): 129-52.

Sakellariou, D. \& N. Galanidou. 2015. Pleistocene submerged landscapes and Palaeolithic archaeology in the tectonically active Aegean region, in J. Harff, G. Bailey \& F. Lüth (ed.) Geology and archaeology: submerged landscapes of the Continental Shelf: 145-78. London: Geological Society.
Simmons, A.H. 2012. Mediterranean island voyages. Science 338: 895-97.

https://doi.org/10.1126/science. 1228880

- 2014. Stone Age sailors: Paleolithic seafaring in the Mediterranean. Walnut Creek (CA): Left Coast.

Strasser, T.F., E. Panagopoulou, C.N. Runnels, P.M. Murray, N. Thompson, P. Karkanas, F.W. McCoy \& K.W. Wegmann. 2010. Stone Age seafaring in the Mediterranean: evidence from the Plakias region for Lower Palaeolithic and Mesolithic habitation of Crete. Hesperia 79: 145-90.

https://doi.org/10.2972/hesp.79.2.145

Strasser, T.F., C. Runnels, K. Wegmann, E. Panagopoulou, F. McCoy, C. Digregorio, P. Karkanas \& N. Thompson. 2011. Dating Palaeolithic sites in southwestern Crete, Greece. Journal of Quaternary Science 26: 553-60. https://doi.org/10.1002/jqs.1482

Sutikna, T., M.W. Tocheri, M.J. Morwood, E.W. Saptomo, Jatmiko, R. Due Awe, S. Wasisto, K.E. Westaway, M. Aubert, B. Li, J.-X. Zhao, M. Storey, B.V. Alloway, M.W. Morley, H.J.M. Meijer, G.D. van den Bergh, R. Grün, A. Dosseto, A. Brumm, W.L. Jungers \& R.G. RoberTs. 2016. Revised stratigraphy and chronology for Homo floresiensis at Liang Bua in Indonesia. Nature 532: 366-69. https://doi.org/10.1038/nature17179

van den Bergh, G.D., Y. Kaifu, I. Kurniawan, R.T. Kono, A. Brumm, E. Setiyabudi, F. Aziz \& M.J. Morwood. 2016a. Homo floresiensis-like fossils from the early Middle Pleistocene of Flores. Nature 534: 245-48. https://doi.org/10.1038/nature17999

van den Bergh, G.D., B. Li, A. Brumm, R. Grün, D. Yurnaldi, M.W. Moore, I. Kurniawan, R. Setiawan, F. Aziz, R.G. Roberts, Suyono, M. Storey, E. Setiyabudi \& M.J. Morwood. 2016b. Earliest hominin occupation of Sulawesi, Indonesia. Nature 529: 208-11. https://doi.org/10.1038/nature16448

van der Geer, A.A.E., G.A. Lyras, L.W. VAN deN Hoek Ostend, J. de Vos \& H. Drinia. 2014. A dwarf elephant and a rock mouse on Naxos (Cyclades, Greece) with a revision of the palaeozoogeography of the Cycladic Islands (Greece) during the Pleistocene. Palaeogeography, Palaeoclimatology, Palaeoecology 404: 133-44. https://doi.org/10.1016/j.palaeo.2014.04.003

Received: 25 July 2016; Accepted: 25 October 2016; Revised: 27 October 2016

(C) Antiquity Publications Ltd, 2017 